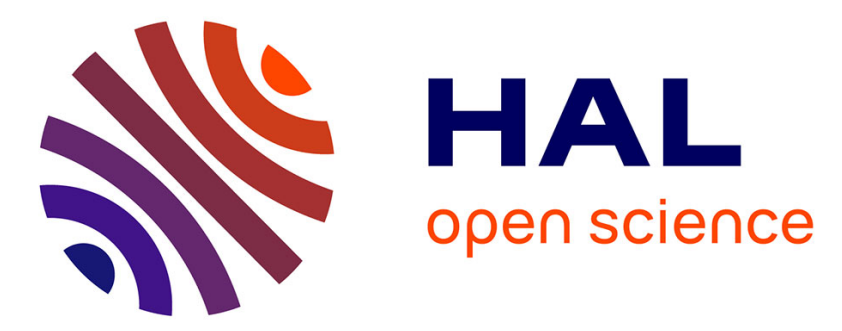

\title{
Challenges in Production and Manufacturing Systems Platform Development for Changeable Manufacturing
}

Daniel G.H. Sorensen, Thomas Ditlev Brunoe, Kjeld Nielsen

\section{To cite this version:}

Daniel G.H. Sorensen, Thomas Ditlev Brunoe, Kjeld Nielsen. Challenges in Production and Manufacturing Systems Platform Development for Changeable Manufacturing. IFIP International Conference on Advances in Production Management Systems (APMS), Aug 2018, Seoul, South Korea. pp.312-319, 10.1007/978-3-319-99704-9_38. hal-02164916

\section{HAL Id: hal-02164916 https://hal.inria.fr/hal-02164916}

Submitted on 25 Jun 2019

HAL is a multi-disciplinary open access archive for the deposit and dissemination of scientific research documents, whether they are published or not. The documents may come from teaching and research institutions in France or abroad, or from public or private research centers.
L'archive ouverte pluridisciplinaire $\mathbf{H A L}$, est destinée au dépôt et à la diffusion de documents scientifiques de niveau recherche, publiés ou non, émanant des établissements d'enseignement et de recherche français ou étrangers, des laboratoires publics ou privés. 


\title{
Challenges in Production and Manufacturing Systems Platform Development for Changeable Manufacturing
}

\author{
Daniel G. H. Sorensen ${ }^{[0000-0001-9395-2411]}$, Thomas Ditlev Brunoe and Kjeld Nielsen \\ Aalborg University, Fibigerstræde 16, DK9220 Aalborg, Denmark \\ danielemp.aau.dk
}

\begin{abstract}
Development of platforms for products has proven a successful way to manage and address several challenges related to increasing variety and accelerating product development cycles. Thus, it is natural to assume that platforms may facilitate similar benefits for manufacturing systems, as they are both technical systems. Production and manufacturing systems platform development is, however, still an area of research lacking maturity. Development of platforms in this field comes with a set of challenges not necessarily found in product platform development. Looking towards other fields of research or science may be necessary to address these challenges. This paper aims to study challenges related to production and manufacturing systems platform development and describe how these have been addressed. It does so through an evolving case study based on four projects with an industrial collaborator. This leads to setting the stage for future research on production platforms.
\end{abstract}

Keywords: Manufacturing systems, Platform, Mass customization, Case study

\section{Introduction}

With increasing product variety, shortened development lifecycles and accelerated time-to-market, manufacturers' ability to adapt is being strained, and addressing this challenge is proving to be a difficult task [1]. The standardisation, consistency and reusability of platforms, which has proven successful in managing product variety [2], is a seemingly attractive choice for managing production variety [3]. Platforms incorporating these aspects in production and manufacturing systems are called production platforms, and can be utilised to achieve appropriate levels of changeability.

Changeability and its underlying classes [4] are common responses to increasing variety as a form of robust process design [5]. For design of manufacturing systems utilising changeability (such as reconfigurable manufacturing), development and design of production platforms remains a challenge during the later design stages [6]. Concepts such as co-development [7], co-platforming [8] and, integrated product and production modelling $[9,10]$ are gaining traction. This highlights a need for coexisting product and production platforms.

Due to the relative immaturity of the production platform field [3], it can be beneficial to draw inspiration from research in other fields dealing with technical systems. 
Product platforms and software architecture are both examples of such research fields, where inspiration has previously been drawn [11-14]. However, manufacturers attempting to develop and utilise production platforms still face numerous challenges. These include the platform development process itself, platform documentation, identification, modelling and utilisation.

This paper presents a series of challenges, lessons, and experiences on production platforms, structured as an evolving case study carried out over a period of three years. To frame the paper, the following research question is formulated:

- Which challenges do mature manufacturers face over time, when developing production platforms?

Firstly, the method for structuring the case study is presented based on design science in information systems research [15]. Second, the evolving case study is introduced, followed by the results and experiences of the case study related to the research framework. Finally, the paper ends with a discussion on the results and future research on production platforms.

\section{$2 \quad$ Method}

Hevner et al. [15] present a conceptual framework for information systems (IS) research by combining the design science and behavioural science paradigms. In the framework, IS research receives input from the environment in the form of requirements or needs, and from a knowledge base in the form of applicable knowledge such as theories, methods and models. This framework lends itself well to carrying out research on platforms, as the IS research framework focuses on developing and building theories and artefacts. Artefacts and theories are subsequently justified and evaluated, in the sense that they must provide some form of utility for addressing a particular problem. Justified theories and evaluated artefacts are added to the knowledge base and applied in an appropriate environment. In this way, the knowledge base itself acts as a platform evolving and being instantiated through IS research. The IS research framework is illustrated in Fig. 1.

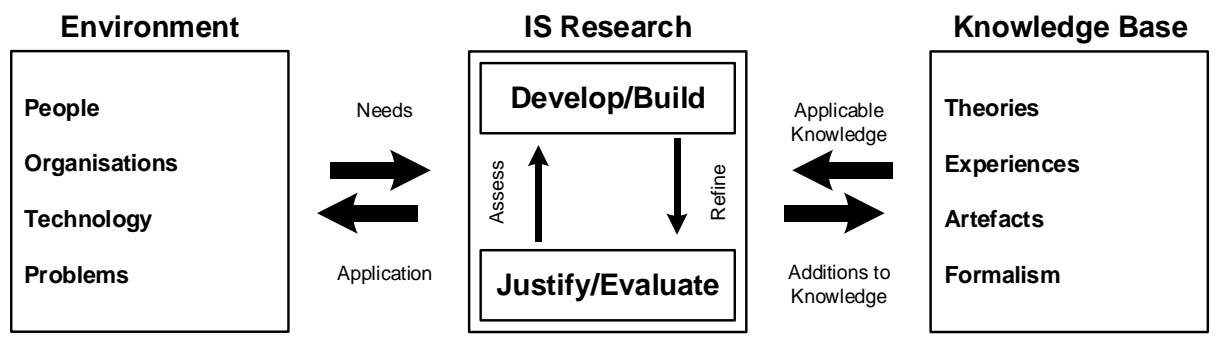

Fig. 1. Simplified illustration of Hevner et al.'s IS research framework [15].

Four types of artefacts are considered in the framework: constructs, models, methods and instantiations. Constructs are languages or templates for defining and com- 
municating problems and solutions, while models use constructs to represent the problem and solution space. Methods are processes for solving problems, and instantiations demonstrate the feasibility of an artefact [15]. Artefacts can also be considered somewhat analogous to the viewpoints and views utilised in software and enterprise architecture [16].

Having used theories and artefacts from various fields during the four projects in the evolving case study, this paper feeds back information to the knowledge base on platforms. Through the case study presented in Sections 3 and 4 theories, methods, models and tools have been applied with varying degrees of success.

\section{Case Presentation}

The case company is a large Danish manufacturer of discrete consumer and OEM products, with most of the production located in Denmark, and a number of other locations in Europe, North America and Asia. Numerous factories, production segments and systems are part of the case study. While mainly focused on the production in Denmark, some factories and systems in other countries are included to provide a comprehensive picture of the production. Included in the scope of the case study is a variety of production systems and corresponding products, ranging from manual to fully automatic systems. The manufactured products are either purely mechanical or mechatronic in nature, and range from small to large product size in the context of the case company.

Initially, the case study included one production segment consisting of five production systems covering five mechanically different products in a family. As work progressed, the scope expanded. Development of production platforms is the overall goal for the on-going case study, with the expected outcome being a method for production platform development based on existing production systems, and a collection of documented production platforms.

In relation to the research framework presented above, the knowledge base for production platforms, and thus for the case study, is very limited. Therefore, the case study employed applicable theories and artefacts from knowledge bases on product platforms, software systems and enterprise architecture, to name a few. By doing this, a contribution to the knowledge base on production platforms can be made. Specific contributions are made in the form of artefacts. The case study environment (including people, organisations and technologies) provides the requirements for evaluating and context for implementing the artefacts below.

- Constructs such as modelling languages and documentation formats typically from related knowledge bases outside the production system area.

- Models developed from constructs to address or frame a specific concern related to a production system or platform development and documentation in general.

- Methods for utilising specific constructs or tools to address or frame a concern and an overarching method for production platform development.

- Instantiations in the form of concrete tools and examples aimed at improving the process of platform development and utilisation. 


\section{$4 \quad$ Results}

Preliminary studies in the case company showed large potential savings in improving system robustness and utilisation. These, amongst several others, are benefits potentially provided by platforms $[1,2]$. As the case study progressed, the understanding of the benefits, nature and purpose of platforms changed, as the following sections illustrate. The sections serve to highlight how, why and where experience was gained, lessons were learned and changes were made to the platforming approach. Fig. 2 shows an overview of the four case study projects covered in this section.

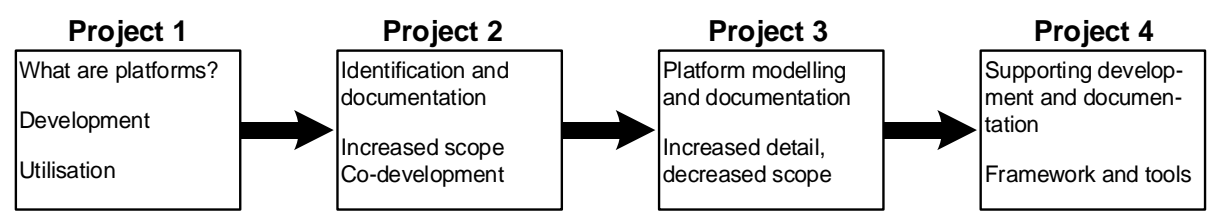

Fig. 2. Overview of the four case study projects. Project 4 is currently in progress.

\subsection{Project 1: What are Production Platforms?}

A persistent challenge throughout the case study, and particularly in the first project, was the focus on product platforms in literature. Along with numerous similar but varying definitions of platforms, this made it difficult to arrive at a consistent and coherent understanding of production platforms. The questions "what are production platforms?", "what are they for?" and "how do we make them?" were the focus in the initial project of the case study. It was the ambition to design reconfigurable manufacturing systems (RMS) via platforms, to achieve robustness and higher utilisation of equipment. At this point, most of the project's few participants had little to no knowledge on platforms. In the same vein, there was a need for clarifying the connection between platforms, RMS and the desired changeability characteristics.

Answering the first two questions, production platforms are defined as a collection of production equipment, interfaces, processes and knowledge from which production systems and their constituent elements can be efficiently derived and developed. To address the third question, a first attempt at an extractive platform development approach was made, basing development on a set of existing systems by selecting and restructuring parts of the systems to create a platform. Five existing systems producing five product variants were mapped to identify the functional elements of each. Function-means trees [17] and generic organ diagrams [18] were then used to identify candidate elements for a platform, and a workshop was carried out to generate new potential platform candidates. The platform candidates were then used to generate new reconfigurable production concepts addressing the needs for changeability. 


\subsection{Project 2: Figuring out Production Platform Development and Documentation}

In the second project, the scope was expanded to an entire factory covering 23 production systems and 25 product architectures. As the scope increased drastically, so did the number of participants. A key challenge in this project was the alignment of the participants' understanding of both platforms, but also the purpose of the project itself. Few had intimate knowledge of platforms, and concrete examples were needed to communicate it further throughout the organisation. Thus, during the second project of the case study, the focus was on identifying and documenting more platform candidates and on increasing the level of detail for a few select platform candidates. Project 2 was a co-development or joint-development project, as platforms for both products and production were under development simultaneously. On this note, a related challenge appeared in improving communication between the two departments. The project was also an attempt at breaking down the figurative "silos" in which each department isolated themselves.

Project 2 was generally carried out according to the Four Loops of Concern (FLC) as described in [11]. This method denoted both the vocabulary and approach for identifying, developing and documenting platforms. It is an iterative method consisting of four loops and four steps to complete each loop. The outcome of each loop is a collection of models addressing a specific set of concerns. For instance, the first loop addresses concerns about functional capability. It uses flow diagrams and functionmeans trees to capture the functional sequence and alternative solutions, respectively.

The results of the second project in the case study was 1) an evaluation of FLC for platform development, 2) several model and instantiation artefacts and 3) an initial documentation format for platforms. Constructs used in creating the models and instantiations include function-means trees, generic organ diagrams, interface diagrams, flow charts, block diagrams, radar diagrams and technical drawings and diagrams.

\subsection{Project 3: Modelling and Documenting Production Platforms}

For project 3, the focus was on modelling platforms and using said model as documentation of the platform. If a platform is to be used, it must be documented, maintained, and its existence must be known to the developers who are to use it. Finding concrete examples of how to document production platforms and store their information, proved an immense challenge. In project 2 of this case study, attempts were made at structuring the development and documentation process, but it still relied on individual text documents with static figures and tables. Current documentation on manufacturing systems consists of potentially hundreds of pages of information, and the document itself can be difficult to locate within the company.

The premise for project 3 was essentially to have a backend model of the platform containing all existing information on that specific platform (relations, properties, capabilities, alternatives, etc.). Based on the concerns of a specific stakeholder, a customised document was to be generated, containing only information relevant to that stakeholder. A number of modelling perspectives, formats and frameworks were con- 
sidered for this task, notably the ArchiMate modelling language and the configurable component framework (CCF) [19]. CCF was selected for its integration of product and manufacturing system platforms in previous studies $[9,10,20]$.

A specific platform candidate designed and developed in-house and carrying out a core process was selected for modelling using the software tool, configurable component modeler (CCM). CCF and CCM model elements of a system as independent configurable components each encapsulating interfaces, interactions, design rationale (constraints, functional requirements and design solutions) and compositional information. The output of CCM was transformed into documentation containing only the desired information addressing a specific set of concerns.

\subsection{Project 4: Supporting Production Platform Development}

Project 4 is currently in progress at the case company. At this stage, a comprehensive platform framework is being created to support the development, documentation and utilisation of platforms. This is an attempt at addressing the persistent challenge of consistency and coherency, both in the vocabulary and in the development process itself. The framework is also a step towards addressing the lack of research and tools in the field of production platforms. It incorporates both artefacts from the previous three projects and new artefacts currently being developed. It is based around a set of conceptual models denoting the structure and vocabulary for the framework, based on the conceptual model by Bossen et al. [14] and the ISO standard (ISO 42010) on architecture descriptions [16]. Two concrete parts of this framework is a classification scheme for production processes and a manufacturing system classification code, both used for identifying candidates for platform development.

The classification scheme is a consolidation of several existing classifications and taxonomies, incorporating four main categories of processes: manufacturing, material handling, test \& inspection, control \& planning. It is a supporting tool for platform candidate identification, with the classification coding facilitating comparison of existing manufacturing systems. Both the scheme and coding are treated in separate upcoming publications.

\section{Discussion \& Future Research}

During the case study, the company progressed through four projects for platform development. The main challenges faced during the projects are summarised in the list below.

- Lack of consistency and coherency in vocabulary and development process.

- Misalignment of participant knowledge on platforms and project scope.

- Miscommunication between separate departments of the manufacturer.

- Lack of examples regarding documentation platforms.

- Lack of research and tools in production platform research. 
In the initial project, knowledge on platforms was minimal. The scope was kept relatively limited to keep the project focused on learning essential aspects of platforms - their nature, development and utilisation. For the second project, the scope was expanded, including more production systems and product families with more variety. Experts for each system were brought in, and the focus was on following a structured method to create concrete examples. During the third project, as the scope was decreased the level of detail was increased, modelling a single element of a platform. The model was used to generate customized documentation on the platform. In the fourth and current project, a comprehensive platform development and documentation framework is under development. It takes advantage of the experiences and artefacts from previous projects, and develops new methods and instantiations.

As mentioned, both a classification scheme for production processes and a manufacturing system classification code is currently being developed. The classification scheme itself is an enabler for the classification code, which builds upon existing group coding systems for manufacturing systems. Using the classification coding, manufacturing systems in a company can be compared against each other in order to identify elements of commonality and potential areas for platforms.

Based on the FLC platform development method, a new and revised method is currently being developed. It utilises the concept of views and viewpoints described in ISO 42010 [16]. The method prescribes both the process (from development to documentation) and tools to support it, such as the previously mentioned classification scheme and coding.

Aside from the above works-in-progress, more research is still needed in the preliminary stages of platform development. This includes quantification of the potential of applying production platforms, and ways to determine the appropriate type or amount of production platforms for a given company [21]. Another area is the modelling of production platforms and subsequent mapping to corresponding product platform models. A sufficient level of modelling and mapping could allow manufacturers to evaluate the producibility of a new product, and help identify necessary changes required to make the product producible.

\section{References}

1. ElMaraghy, H., Schuh, G., ElMaraghy, W., Piller, F., Schönsleben, P., Tseng, M., Bernard, A.: Product variety management. CIRP Annals - Manufacturing Technology 62(2), 629652 (2013).

2. Simpson, T. W.: Product platform design and customization: Status and promise. AI EDAM 18(1), 3-20 (2004)

3. Bossen, J., Brunoe, T. D., Nielsen, K.: Platform-based production development. In: Umeda S., Nakano M., Mizuyama H., Hibino N., Kiritsis D., von Cieminski G. (eds.) Advances in production management systems: Innovative production management towards sustainable growth, pp. 53-61. Springer International Publishing (2015).

4. ElMaraghy, H. A., Wiendahl, H.: Changeability - an introduction. In: ElMaraghy H.A. (ed.) Changeable and reconfigurable manufacturing systems, pp. 3-24. Springer London (2009). 
5. Salvador, F., de Holan, P. M., Piller, F. T.: Cracking the code of mass customization. MIT Sloan Management Review 50(3), 71-78 (2009).

6. Andersen, A., Brunoe, T. D., Nielsen, K., Rösiö, C.: Towards a generic design method for reconfigurable manufacturing systems: Analysis and synthesis of current design methods and evaluation of supportive tools. J.Manuf.Syst. 42, 179-195 (2017).

7. Michaelis, M. T., Johannesson, H.: From dedicated to platform-based co-development of products and manufacturing systems. In: ElMaraghy H.A. (ed.) Enabling manufacturing competitiveness and economic sustainability, pp. 196-202. Springer, Berlin, Heidelberg (2012).

8. ElMaraghy, H., Abbas, M.: Products-manufacturing systems co-platforming. CIRP Annals - Manufacturing Technology 64, 407-410 (2015).

9. Michaelis, M. T., Johannesson, H., ElMaraghy, H. A.: Function and process modeling for integrated product and manufacturing system platforms. Journal of Manufacturing Systems 36, 203-215 (2015).

10. Landahl, J., Levandowski, C., Johannesson, H., Söderberg, R., Wärmefjord, K., Carlson, J. S., Kressin, J., Isaksson, O., Vallhagen, J.: Using product and manufacturing system platforms to generate producible product variants. Procedia CIRP 44, 61-66 (2016).

11. Sorensen, D. G. H., Bossen, J., Bejlegaard, M., Brunoe, T. D., Nielsen, K.: Production platform development through the four loops of concern. In: Customization 4.0. Springer, Berlin (2018).

12. Benkamoun, N., ElMaraghy, W., Huyet, A., Kouiss, K.: Architecture framework for manufacturing system design. Procedia CIRP 17, 88-93 (2014).

13. Jepsen, A. D.: Architecture Descriptions. A Contribution to Modeling of Production System Architecture. Ph.D. Thesis. Technical University of Denmark (2014).

14. Bossen, J., Brunoe, T. D., Bejlegaard, M., Nielsen, K.: Conceptual model for developing platform-centric production architectures. In: Bellemare J., Carrier S., Nielsen K., Piller F.T. (eds.) Managing complexity, pp. 83-98. Springer International Publishing, Cham (2017).

15. Hevner, A. R., March, S. T., Park, J., Ram, S.: Design science in information systems research. MIS Quarterly 28(1), 75-105 (2004).

16. ISO, IEC, IEEE: Systems and software engineering - architecture description. International Organization for Standardization ISO/IEC/IEEE 42010:2011(E) (2011).

17. Andreasen, M. M., Hansen, C. T., Cash, P.: Function reasoning. In: Andreasen M.M., Hansen C.T., Cash P. (eds.) Conceptual design: Interpretations, mindset and models, pp. 267-305. Springer International Publishing, Cham (2015).

18. Harlou, U.: Developing product families based on architectures. Ph.D. Thesis. Technical University of Denmark (2006).

19. Claesson, A.: A Configurable Component Framework Supporting Platform-Based Product Development. Ph.D. Thesis. Chalmers Tekniska Högskola (2006).

20. Levandowski, C. E., Corin-Stig, D., Bergsjö, D., Forslund, A., Högman, U., Söderberg, R., Johannesson, H.: An integrated approach to technology platform and product platform development. Concurrent Engineering 21(1), 65-83 (2013).

21. Andersen, A., ElMaraghy, H., ElMaraghy, W., Brunoe, T. D., Nielsen, K.: A participatory systems design methodology for changeable manufacturing systems. Int J Prod Res, 1-19 (2017). 